\title{
Socio-medical analysis of patients aged 0-6 years reporting to the dentist
}

\begin{abstract}
Introduction. The results of epidemiological and socio-medical studies of specific age groups in Poland indicate that tooth decay and periodontal diseases still pose a significant health problem.

Aim. The aim of the study was the assessment of the reasons for reporting to the dental office and the assessment of oral health in children aged 0-6 years.

Material and methods. The study comprised 45 patients in the preschool age (2-6 years old), who for the first time reported in 2015 to the dental office, which offers treatment under the framework of an agreement with the National Health Fund or for a fee. Gender, age, the place of residence and the reason for the reporting to the dentist were analyzed. The place of residence was a village, a town of less than 200 thousand inhabitants or the city of more than 200 thousand inhabitants. The reason for reporting to the dental office was a check-up visit, toothache or loss of filling. Dental condition was assessed by calculating the dmf index. The results were statistically analyzed.

Results. Among the surveyed, there were no children younger than 2-year-olds. It was found that the dmf index was ranging in an individual patient from 0 to 20 , in half of them the dmf index value was $\leq 7$, while in all of the patients the average dmf index was 6.42 . The percentage of respondents with $\mathrm{dmf}=0$ was significantly higher among children living in the city than children living in rural areas.

Conclusion. It is necessary to intensify educational activities concerning oral health of children, addressed to pregnant women, parents and people from the living environmental of a little child. This applies in particular to promoting early reporting to the first ever, the adaptive visit of a child to the dentist, frequent and regular check-up visits, during which, regardless of the examination, prophylaxis or treatment activities can be carried out if necessary.
\end{abstract}

Keywords: children, a visit to the dentist, dmf.

DOI: $10.1515 /$ pjph-2016-0005

\section{INTRODUCTION}

Tooth decay and periodontal diseases pose a very serious health problem in Poland. This is demonstrated by the results of national epidemiological and socio-medical studies of certain index age groups of the population that have been carried out according to the recommendations and on the basis of the WHO clinical states classification criteria, since the last decade of the last century [1].

According to the principles adopted by the World Health Organization (WHO) for monitoring the state of oral health, the youngest age groups of the population were studied with the 2 years' interval, which results from the carious process in the primary and the permanent immature teeth. Epidemiological studies have revealed that the main problems with oral health among Polish children is a high incidence and severity of early childhood caries in children under 3 years of life, failure to out either checkups of primary teeth or the prevention and conservative treatment of caries in preschool children, as well as low percentage of children without tooth decay at the age of 5 years $[1,2]$.

Obviously, oral health, and particularly tooth decay as a civilization disease does not depend on therapeutic actions of dentists, but the healthy behaviors of individuals and dental prevention programs. Oral health of the child is affected mainly by the lifestyle, and thus behavioral patterns in relation to the masticatory system and environmental conditions - social, political, economic and natural. Furthermore, the health care system, including dental care and individual factors [1,2].

\section{AIM}

The aim of the study was the assessment of the reasons for reporting to the dental practice and the oral health of children aged 0-6 years.

\footnotetext{
${ }^{1}$ Chair and Department of Paedodontics, Medical University of Lublin, Poland

${ }^{2}$ Department of Dental Prosthetics, Medical University of Lublin, Poland

${ }^{3}$ Department of Mathematics and Medical Biostatistics, Medical University of Lublin, Poland
} 


\section{MATERIAL AND METHODS}

The study comprised 45 patients in the preschool age (2-6 years), who for the first time ever reported in 2015 to the dental practice in Lublin, which offers treatment within the framework of an agreement with the National Health Fund or for a fee. We analyzed the gender, age, place of residence and the reason for the reporting. The place of residence was determined as a village, a town of less than 200 thousand inhabitants or the city of more than 200 thousand inhabitants. The reason for reporting to the dental practice was a checkup visit, toothache, or loss of filling. Dental condition was assessed by calculating the dmf index. The results were statistically analyzed using the Mann-Whitney U test, Student's t-test with grouping variable and $\mathrm{Chi}^{2}$.

\section{RESULTS}

The study comprised 45 children aged 2-6 years. Half of the respondents did not exceed 5 years, mean age was 4.91 years. Girls accounted for $55.56 \%(\mathrm{n}=25)$, while boys accounted for $44.44 \%(n=20)$. The place of residence of the majority of respondents $82.22 \%(n=37)$ was the city of more than 200 thousand inhabitants, village $-15.56 \%(\mathrm{n}=7)$ and one child $(2.22 \%)$ came from the town of less than 200 thousand inhabitants.

The main reason for reporting to the dentist was a check-up visit - such an answer was given by $93.33 \%(n=42)$ of the parents surveyed, while the toothache was the cause of reporting for $6.67 \%$ of the respondents $(n=3)$.

In the analyzed group of children, we found that the number of carious lesions ranged from 0 to 20 . In half of the respondents the number $d$ was not higher than 3 , while the average number $\mathrm{d}$ for all respondents was 4.51.

For further analysis, the children were divided into two groups. The first group included patients who showed no evidence of tooth decay $(\mathrm{d}=0)$, the second one, in which the $\mathrm{d}$ value was higher than 0 . It was calculated that in $36.0 \%$ of girls and $15.0 \%$ of boys the $d$ value was 0 , while the incidence of tooth decay was observed in $64.0 \%$ of girls and $85.0 \%$ of boys. The observed differences were statistically significant (Pearson's $\mathrm{Chi}^{2}=3.85 ; \mathrm{df}=1 ; \mathrm{p}=0.049$ ) (Figure 1).

Statistical analysis showed that the average value of the number of decayed teeth in children from the city differs significantly from the average number $d$ in the group of patients coming from the village. In children who live in the city, the average number $d$ was 3.31. In children living in rural areas the average value of the number $d$ was 5.57. It was found that the percentage of respondents with a number $\mathrm{d}=0$ was statistically significantly higher among children living in the city $(28.95 \%)$ than children living in rural areas $(14.29 \%)$ (Pearson's $\mathrm{Chi}^{2}=4.49 ; \mathrm{df}=1 ; \mathrm{p}=0.04$ ) (Figure 2).

A statistically significant relationship was confirmed between the cause of the child reporting to the dentist and the number of cavities. Among the children who referred to a dentist for a check-up visit (the majority of parents in this group stated that they reported regularly to these visits), the average number $d$ was 4.05 , while the average value of the number $d$ of children who came with toothache was 11.00.

The number of primary teeth missed as a result of dental caries (m) was in the range $0-2$. In 39 out of 45 children tested, the number $m$ was 0 , therefore, the variable " $m$ " was not subjected to statistical analysis.

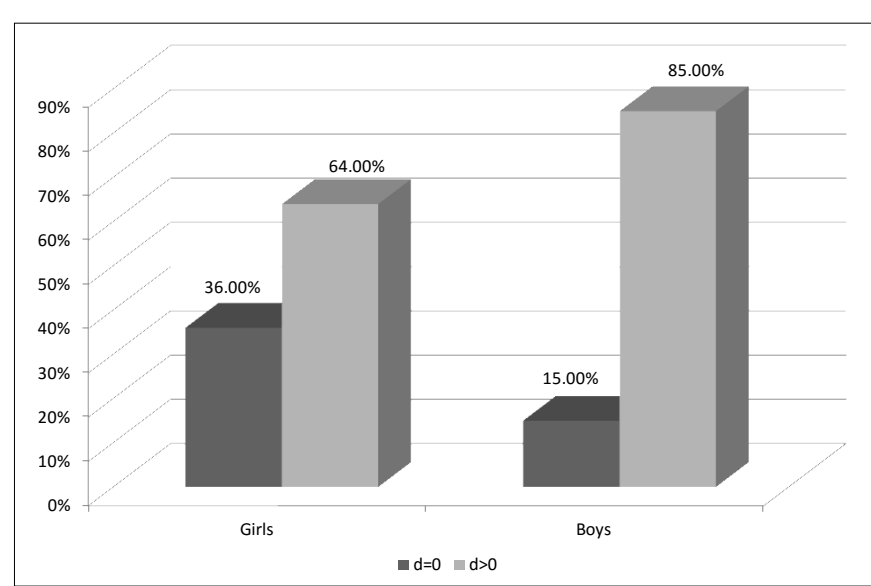

FIGURE 1. The value of the number $d$ with respect to the gender of the respondents.

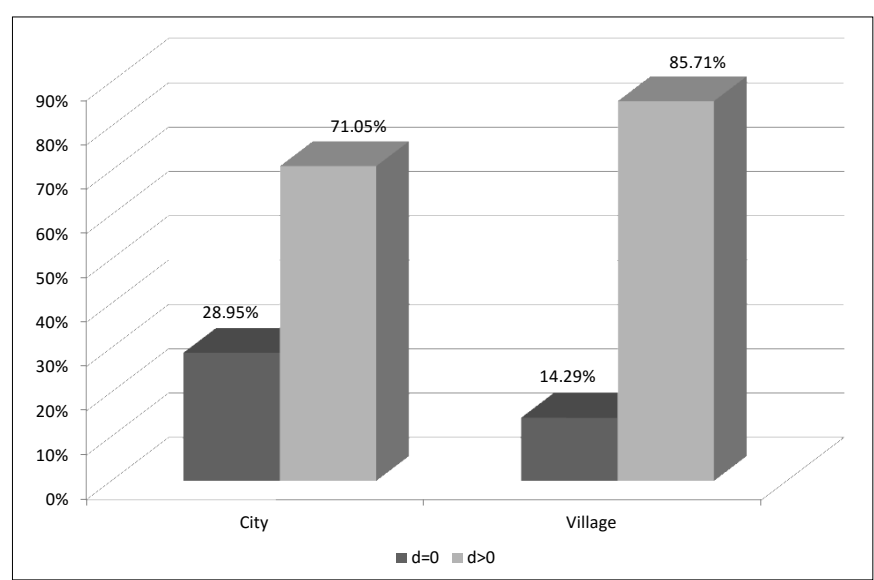

FIGURE 2. The number of carious lesions with relation to the place of residence of the respondents.

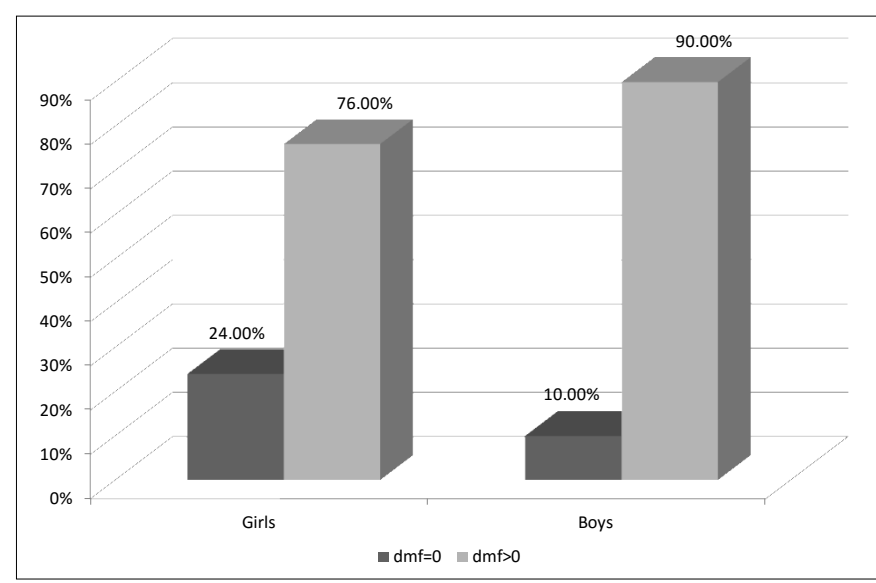

FIGURE 3. The dmf index in relation to the gender of the respondents.

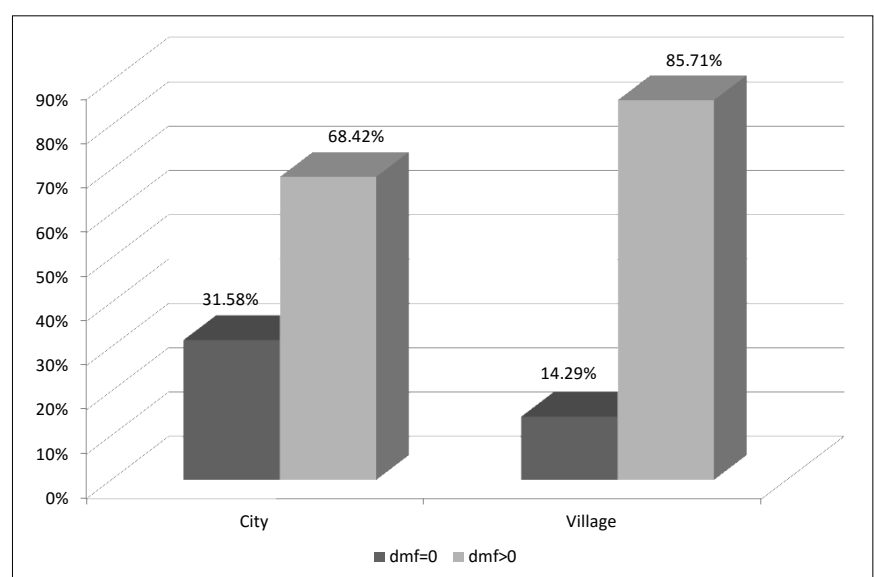

FIGURE 4. The dmf index in relation to the place of residence of the respondents. 
The number of fillings (f) was in the range $0-8$; in half of the tested respondents the number $\mathrm{f}$ was equal to 0 , whereas the average number of fillings in the studied group of children was 1.76 .

Place of residence, age of the child and the cause of reporting to the dentist did not affect in a statistically significant way the number of fillings (Mann-Whitney test $\mathrm{Z}=1.03$; $\mathrm{p}=0.26$ ); $(\mathrm{r}=0.02 ; \mathrm{p}=0.89)$; (Mann-Whitney test $\mathrm{Z}=1.41 ; \mathrm{p}=0.15)$.

The $\mathrm{dmf}$ index in the studied group of children was in the range $0-20$, in half of the respondents it was not higher than 7 . The average value of the dmf index for the studied group was 6.42 .

The children participating in the research were divided into two groups for further statistical analysis, taking into account the dmf index. The first group consisted of children whose dmf index was equal to 0 , while the other group included subjects for whom dmf index was higher than 0 . It was found that statistically significantly more frequently $\mathrm{dmf}$ index equaling to 0 occurs in girls $(24.0 \%)$ than boys $(10.0 \%)$ (Pearson's $\mathrm{Chi}^{2}=3.49 ; \mathrm{df}=1 ; \mathrm{p}=0.03$ ) (Figure 3).

Among the children living in the city average dmf index was 6.0, while among children living in rural areas the average value of the dmf index was 8.71. The observed differences were statistically significant $(\mathrm{t}=3.33, \mathrm{df}=43, \mathrm{p}=0.019)$. It was also shown that the percentage of respondents with dmf index equal to 0 was significantly higher among children living in the city (31.58\%) than children living in rural areas $(14.29 \%)$ (Pearson's $\mathrm{Chi}^{2}=3.78 ; \mathrm{df}=1 ; \mathrm{p}=0.039$ ) (Figure 4).

Among the children who reported to the dentist for a checkup, the mean dmf index was 6.09. In children who reported because of toothache the mean dmf index was 10.96 . The observed differences were statistically significant.

\section{DISCUSSION}

To begin with, the authors would like to emphasize that initializing the project described in this research paper, they had not expected so low a number of children reporting to the dentist.

Disturbing is the result of own studies on the basis of which in the analyzed period of one year (2015) parents did not report to the dental office with children before the age of the child's second year of life. This may be the result of inadequate educational activities aimed at pregnant women and parents of young children, both on the part of dentists, but also medical doctors, specialists in pediatrics and family medicine. It should be noted that the dental practice in Lublin, in which the study was carried out operates both on private basis and has an agreement with National Health Found (NHF) (free of charge visits). So, the patients were not constrained by financial considerations.

It is known that respectively early visit to the dentist - the so-called adaptive visit makes it possible to conduct a clinical examination to provide parents with advice on the proper oral hygiene of the child and the correct eating habits, as well as planning preventive and therapeutic procedures as needed. Other studies show that many parents report to the dentist with the children after their second year of life, just as was the case in our study. With younger children, parents more often report to doctors than dentists [3-7]. Epidemiological studies conducted in Poland show that over $60 \%$ of mothers of children aged 3 years did not report with their child to the dentist [2].
The American Academy of Pediatric Dentistry (AAPD) recommends that the first dental visit of a child should take place within 6 months from the eruption of the first deciduous teeth, no later than at 12 months of age $[8,9]$.

In our study, the vast majority of parents reported that the cause of visits to the dentist was checking of the child's dentition. This proves that parents are aware of the need for regular reporting to the dentist with their children. Adequately frequent visits to the dentist allow performing preventive treatments and early detection of caries and effective treatment [4, $9,10]$.

The authors conducting epidemiological studies since the 90 s of the last century in other countries have shown steady growth in the referrals of the children to dental surgeries and at the same time lowering the value of average $\mathrm{dmf}$ index at patients [11-14]. Similar regularity was found in our study, in which the average value of $\mathrm{dmf}$ index was significantly lower in children presenting for a check than in children who present with a toothache.

The results of epidemiological studies conducted in Poland for the World Health Organization showed that the average value of dmf index for 3-year-old children was 3, and 5-yearold children was equal to 5.1 [2]. The average value of dmf index in our study was 6.0, with an average value of component $\mathrm{d}=4.51$, which confirms high severity of dental caries.

\section{CONCLUSION}

In conclusion, it is necessary to intensify educational activities concerning oral health of children, addressed to pregnant women, parents and people from the living environmental of a little child. This applies in particular to adequately early reporting of the child to the first ever adaptive visit to the dentist, adequately frequent, regular check up visits, during which, regardless of the examination, prophylaxis or treatment can be carried out when necessary.

\section{REFERENCES}

1. Michalak E, Łoboda J, Chomyszyn-Gajewska M. Przyczyny zgłaszania się pacjentów do krakowskich gabinetów stomatologicznych w latach 2005-2006 i 2013-2014. Przegl Epidemiol. 2015;69:913-8.

2. Minister Zdrowia. Monitorowanie stanu zdrowia jamy ustnej populacji polskiej w latach 2013-2015. [http://docplayer.pl/35359-Minister-zdrowia-monitorowanie-stanu-zdrowia-jamy-ustnej-populacji-polskiej-wlatach-2013-2015.htmlProgram na lata 2013-2015]

3. Darmawikarta D, Chen Y, Carsley S, et al. Factors associated with dental care utilization in early childhood. Pediatrics. 2014;133:1594-600.

4. Junqueira Camargo MB, Barros AJD, Frazão P, et al. Predictors of dental visits for routine check-ups and for the resolution of problems among preschool children. Rev Saúde Pública. 2012;46:1-10.

5. Kuthy RA, Kavand G, Momany ET, et al. Periodicity of dental recall visits for young children first seen in community health centers. J Pub Health Dent. 2013;73:271-9.

6. Mantonanaki M, Koletsi-Kounari H, Mamai-Homata E, Papaioannou W. Prevalence of dental caries in 5-year-old Greek children and the use of dental services: evaluation of socioeconomic, behavioural factors and living conditions. Int Dent J. 2013;63:72-9.

7. Morris AJ, Nuttall NM, White DA, et al. Patterns of care and service use amongst children in the UK 2003. Br Dent J. 2006;200:429-34.

8. Bruzda-Zwiech A, Filipińska R, Szydłowska-Walendowska B, et al. Stomatologiczne zachowania prozdrowotne 4-5-letnich dzieci w świetle badań ankietowych rodziców. Dent Med Probl. 2012;49:272-8.

9. Grzesiak I, Kaczmarek U. Pierwsza wizyta dziecka w gabinecie stomatologicznym. Dent Med Probl. 2006;43:433-7. 
10. Hsu U, Hui BK, Pourat N. Recall compliance and incidence of dental caries among underserved children. J Calif Dent Assoc. 2015;43:77-81.

11. Almerich-Silla JM, Boronat-Ferrer T, Montiel-Company JM, Iranzo-Cortés JE. Caries prevalence in children from Valencia (Spain) using ICDAS II criteria, 2010. Med Oral Patol Oral Cir Bucal. 2014;19:574-80.

12. Frencken JE, de Amorim RG, Faber J, Leal SC. The Caries Assessment Spectrum and Treatment (CAST) index: rational and development. Int Dent J. 2011;61:117-23.

13. Mariño RJ, Calache H, Whelan M. Socio-demographic profile of child and adolescent users of oral health services in Victoria, Australia. Cad Saude Publica. 2014;30:1903-11.

14. Vermaire JH, Poorterman JHG, van Herwijnen L, van Loveren C. A Threeyear randomized controlled trial in 6-year-old children on caries-preventive strategies in a general dental practice in the Netherlands. Caries Res. 2014;48:524-33.
Corresponding author

Jolanta Szymańska

Chair and Department of Paedodontics, Medical University of Lublin

Karmelicka 7 Str., 20-081 Lublin

E mail: szymanska.lublin@gmail.com 